\title{
Multi-criteria assessment of the appropriateness of a cooking technology: a case study of the Logone Valley
}

Mentore Vaccari ${ }^{\mathrm{a}, *}$, Francesco Vitali ${ }^{\mathrm{a}}$, Terry Tudor ${ }^{\mathrm{b}}$

${ }^{a}$ Research laboratory for Appropriate Technologies for Environmental Management in resourcelimited Countries (CeTAmb Lab), Department of Civil, Environmental, Architectural Engineering and Mathematics, University of Brescia, Brescia, Italy

${ }^{\mathrm{b}}$ The Faculty of Arts, Science and Technology, University of Northampton, Northampton, NN2 7JD, UK

* Author to whom correspondence should be sent: Email: mentore.vaccari@unibs.it; Tel.: +39-030-371-1300; Fax: +39-030-371-1213.

\begin{abstract}
The choice of fuel for cooking, particularly in rural areas, can lead to significant socio-economic and environmental impacts amongst households. Using the Logone Valley on the border between Chad and Cameroon as the case study region, this study sought to evaluate appropriate cooking technologies for the case study region. Several alternatives to traditional three-stone fire were evaluated, including the: ceramic stove, Centrafricain stove, parabolic solar cooker, biodigester, LPG stove, and mlc rice husk stove. Four main clusters were investigated, structuring quantifiable indicators for financial, environmental, social and health related impacts of the use of a certain energy technology. The findings suggest that the Centrafricain stove alone or in combination with the mlc stove, was the most appropriate cooking technology for use in the case study region. These technologies were more appropriate than the traditional cooking system of the three stone fire. The use of four clusters of criteria, within a weighted system, coupled with the views of users,
\end{abstract}


experts and literature, as well as the scope of the criteria employed enabled a reliable and valid approach to understanding the most appropriate cooking technology to recommend.

\section{Keywords}

Appropriate technology; MCA; Cookstove; Three-stone fire; Wood

\section{Introduction}

The three-stone open fire is the most prevalent fuel-using technology to cook in sub-Saharan Africa and many other developing countries like Peru and India (IEA, 2015; Leavey et al., 2015; Kucerova et al., 2016; WEO, 2016; Kowsari et al., 2017). Indeed, firewood is the primary source of energy amongst households in many developing countries and can be used for cooking even in the absence of a 'stove' (Sosa et al., 2014; Mensah and Adu, 2015). However, use of such cooking technologies are not without disadvantages, including smoke, public health risks - primarily related to respiratory illnesses, low efficiency and high fuel consumption (Venkatamaran et al., 2010; WHO, 2016). On the other hand, there are significant benefits from the use of improved cookstove (ICS) approaches including the emission of warmth and light, the ease of use, the production of (clean) smoke useful to preserve food or to chase away mosquitoes in malariainfested areas and the improvement of family living conditions (WHO, 2016).

Previous models of households switching between different types of fuels for cooking, largely dismiss the importance of active (and strategic) decision making by consumers and their responsiveness to structural factors such as relative fuel prices (e.g. Hiemstra-van der Horst and Hovorka 2008). Indeed, previous studies and models have tended to link household energy choice mainly to a kind of neoclassical consumer behaviour basing their preference primarily on economic convenience (Arnold et al., 2006; Patel et al., 2016). However, the energy transition is often driven not by an emerging desire for modern fuels, but rather by socio-economic conditions (Correa et al., 2014). This is particularly true in rural contexts, where an integrated approach to understanding household energy choice is required, given the number of endogenous (e.g. lifestyles and incomes) and exogenous (e.g. fuel prices) factors affecting such a choice (Kowsari and Zerriffi 2011; Li et al, 2011; Bruce et al., 2013; Debnath et al., 2016). 
Financial and technical criteria have generally been employed in understanding the decision-making process for fuel choice. However, these processes are multidimensional, involving a range of economic, technical, environmental, political and social factors (Karanfil 2009; Li et al., 2011). Thus understanding the decisionmaking processes of householders choice of fuel requires a multi-criteria decision support approach that combines technical and non-technical criteria (Henao et al., 2011; Vaccari et al., 2012; Vitali et al., 2013; Vitali and Vaccari, 2013; Kahraman and Kaya 2010; Parmigiani et al., 2014). Therefore, the key innovation of the study was the multi-criteria approach, which unlike previous studies, enabled a more holistic evaluation and conclusions to be reached.

Using the Logone Valley on the border between Chad and Cameroon as the case study region, this study aimed to evaluate and suggest appropriate cooking technologies for the case study region. This is the first empirical study known to the authors that evaluates the main cooking technologies within a Sub-Sahara setting, using a multi-criteria approach. As illustrated in Fig. 1, the Logone Valley forms part of the international boundary between Chad and Cameroon. The project was focused around the towns of Bongor and Yagoua.

\section{INSERT FIGURE 1 HERE}

\section{Methods}

Four main clusters of criteria were investigated, structuring quantifiable indicators for financial, environmental, social and health related impacts of the use of a certain energy technology. The weight systems adopted were chosen in order to consider the features of each technology according primarily to their relevance to the local needs.

The technological alternatives selected were among options available on the local market at the time of the study. The ranking criteria considered were adopted in order to use quantifiable variables and representative clusters of the sector impacted at household level by the cooking technologies. In addition to the households, 10 experts in the field were also surveyed. The selection of these experts was based on their knowledge of 
the: (1) technologies being evaluated and (2) energy needs of households in the geographical area. Their views therefore served to contextualise the key findings from the households.

\subsection{Technological alternatives evaluated}

Based primarily on Vitali et al. (2013), six alternative cooking technologies were evaluated against the traditional existing three-stone fire: ceramic and Centrafricain ICSs, which are fed with wood, LPG stoves, biodigesters, parabolic solar cookers and, finally, a rice husk stove. The energy recovery of rice husk (a locally available waste biomass), served as a renewable natural resource that was free, and therefore could provide especially low income classes in peri-urban areas with a cheap substitution fuel for wood (Oanh et al., 2005; Vitali et al., 2013; Parmigiani et al, 2014). However, the use of rice husk can be an unreliable option due both to the unavailability of sufficient quantities and their unverified adaptability to all local cooking practices. There has been extensive work on the parabolic solar cooker as an alternative technology in developing countries, which has been shown to work well (e.g. Pohekar and Ramachandran, 2006; Harmim et al., 2014; Sosa et al., 2014). However, given the evident limitations caused by dependence on weather conditions, it can serve only as a partial substitutive energy source for traditional fuels.

\subsection{Choice of criteria}

There are a number of potential indicators that might be considered in the evaluation of the appropriateness of a household energy technology. For example, these might include air quality, feasibility, income generation, Disability-adjusted life years (DALYs), efficiency, and capital and operation costs (Johnson et al., 2009; García-Frapolli et al., 2010; Vitali et al., 2013; Harijan and Uquaili, 2013; Bruce et al., 2013). These indicators have differing levels of significance and influence, which can make modelling a challenge. Moreover, the ease of gathering the data largely depends on the level of the evaluation to be done (i.e. from global and national, to local, down to household level), and the material barriers posed by the project/action being assessed (e.g. the time and financial resources available, availability and reliability of historical local data, support and collaboration of local authorities and institutions, and the active participation of the local population). 
Given the complexity of the issues and the need to undertake a holistic evaluation, a multi criteria decision analysis (MCDA) approach was adopted. In this case, based on previous authors who have adopted a similar approach, the criteria should take account of social/ethical, technical, organizational and economic indicators (e.g. Ilskog and Kjellström; Kahraman and Kaya, 2010; Kucerova et al., 2016). As the study was undertaken within a community setting, issues around health, rather than organizational were considered, as has been utilized by previous studies (Vitali and Vaccari, 2013; Leavey et al., 2015; WHO, 2016). . Four main clusters were considered in the building of the evaluation matrix, according to the impacts assessed on the field. The key quantitative indicators considered representative of the relative cluster can be outlined as:

- C1: financial - Cooking energy expenditure

- C2: health related - Exposure to CO concentration

- C3: environmental - $\mathrm{CO}_{2 \mathrm{eq}}$ emissions

- C4: social - Concordance with users' preferences

All of the indicators were structured so that the lower the value obtained, the lower the negative impact. All values obtained in the evaluation matrix were normalized to the maximum of each row in order to make the data homogenous and comparable.

\subsubsection{1. $\quad C_{1}$ financial impact: cooking energy expenditure}

Generally, financial impact is determined by the sum of the capital cost for the purchase of the cooking system/s and the fuel expenditure (García-Frapolli et al., 2010; Vitali et al., 2013). The indicator takes into account the useful life of the system, the overall efficiency of the combination 'fuel/stove' in the provision of the net energy needed for cooking purposes and the total amount of fuel purchased. To reduce the complexity, no changes for the increase of fuel price or other possible evolutions of the local energy market were taken into account. 
Fuel expenditure was calculated for a typical household in the case study region (family size $=9$ members). Daily fuel consumption was considered for the technologies considered based on tests from previous studies performed on site (Parmigiani et al., 2014). For alternative systems, the fuel purchased quantity was reduced by the share covered by the use of other energy sources (rice husk as a waste biomass and solar energy), which were considered as 'free'. For the biodigester, the fuel cost was assumed to be free, as the system was fed with organic waste and cow manure which were available free of cost for households adopting such a system. As experimental data about LPG consumption were not available, the minimum standard suggested by Practical Action (2011) for such a fuel was employed.

\subsubsection{2. $\quad C_{2}$ health impact: exposure to $C O$ concentration}

The estimation of DALYs due to indoor air pollution (IAP) exposure is probably the most recognized and reliable indicator for evaluating public health impacts (Harijan and Uquaili, 2013; Bruce et al., 2013). Similarly, local incidence of IAP related diseases and pollutant specific biomarkers are indicators that effectively describe the effect of a cooking technology on the users. Exposure to and quality of indoor air pollution may be used, with proper assumptions and limitations, as indirect indicators of the heath impact that a certain cooking technology may have on the user (Li et al., 2011).

The impact of the use of a stove on the indoor air quality was taken as an indicator of the possible health consequences. However, the reduced quantity of measurement on the field and the lack of data regarding the local burden of diseases linked to the exposure to this pollution limited the completeness of this criterion. Carbon monoxide (CO) indoor concentrations for the three stone fire and the Centrafricain ICS were measured on site (Parmigiani et al., 2014). The CO concentrations of technologies were calculated as a weighted sum of the specific concentration values according to the share of energy need covered by the relative source. Other cooking times were calculated proportionally using a time factor calculated on the basis of WBT results (Vitali and Vaccari, 2013). WHO (2010) suggests that the reference guideline for longer-term average concentration of carbon monoxide is the 8-hour. Thus, the average 8-hour CO concentrations $\overline{\mathrm{CO}}_{8 h i}$ were calculated when available from field-monitoring or using a time factor calculated 
on the basis of the WBT outputs) for each cooking system considered. The total exposure of users $\operatorname{Exp}_{c o}$ was calculated according to average daily cooking time $t_{i}$ assumed for each device on the basis of tests performed on site.

$$
c_{2}=\text { exposure }_{C O}=\sum_{i} \overline{C O}_{8 h i} * t_{i}
$$

\subsubsection{3. $C_{3}$ environmental impact: $\mathrm{CO}_{2}$ eq emissions}

$\mathrm{CO}_{2}$ emissions were calculated by summing the emission contribution of each fuel used, multiplied by the relative emission factor. The emission factors were taken from Johnson et al. (2009) both for wood open fire and liquid petroleum gas (LPG). No field measurements were possible for the ICS and the mlc rice husk stove, thus the same emission factor for wood open fire was used. Such an approach is acceptable as similar $\mathrm{CO}_{2}$ emission values have been reported for open fire and improved wood stove with or without chimney (e.g. Johnson et al., 2009). While wood was not considered a renewable resource for the purposes of these analyses, due to the existing unsustainable management at the time of the study, rice husk was considered carbon neutral. Furthermore, open burning of rice husk was a common practice in the rural areas, thus the energy recovery of such a biomass as alternative fuel did not add further emissions. The biogas emission factor was considered the same as for LPG.

Greenhouse gas (GHG) emissions and other aspects linked to a global environmental education and sensitivity are usually neglected. Nevertheless there is a growing debate in the scientific community about this topic and in particular about the contribution of household combustion devices to GHG emissions (e.g. Ghilardi et al., 2009; Bansal et al., 2013; Giuntoli et al., 2015). Thus these aspects were also taken into account in the evaluation. The impact on GHG emissions of switching to advanced biomass technologies and LPG is very difficult to quantify, because of the diversity of factors involved (e.g. the particular fuels, the types of stove and whether the biomass used in replaced by new planting and that a sustainable forestry management is in place). It is widely accepted that improved stoves and greater conversion efficiency would result in emission reductions (Lee et al., 2013; Lewis et al., 2015). $\mathrm{CO}_{2}$ emissions were calculated by 
summing the emission contribution of each fuel $i$, given by the specific fuel use $F_{i}$ multiplying the relative emission factor $E F_{i}$ as show in the equation below.

$$
c_{3}=E_{\mathrm{CO}_{2}}=\sum_{i} F_{i} * E F_{i}
$$

\subsubsection{4. $\quad C_{4}$ social impact: concordance with users' preferences}

Social impact was evaluated by ranking the different stove models according to the concordance with the preferences. A qualitative score ( $s_{i}$ ranging from 0 to 4 ) was assigned by the researchers to the following characteristics: fuel savings, charcoal production, heat conservation, good food taste, cooking speed, transportability, easiness of use, adaptability to traditional cooking practices, durability, hygiene, cleanliness and safety (Vitali and Vaccari, 2013). In the case study area, there was a wide network of wood sellers. Therefore, the time spent collecting and processing the fuel was assumed to be negligible and thus not included in the calculations. The final score was derived from the sum of the sub-score for each characteristic, and indicates the capacity of the technology to meet the users' preferences.

$$
c_{4}=\sum_{i=1}^{12} s_{i}
$$

\subsubsection{Structure of the evaluation matrix}

In the analysis, a normalized indicator $a_{i, j}$ was used for each technological alternative $A_{j}$ for each criterion

$C_{i}$. The indicator was based on an interval standardization method, with the following equation:

$$
a_{i, j}=c_{i, j}-\min \left\{c_{i, 1}, \ldots, c_{i, j}\right\} / \max \left\{c_{i, 1}, \ldots, c_{i, j}\right\}-\min \left\{c_{i, 1}, \ldots, c_{i, j}\right\}
$$

Scores were standardized to values between zero and one with a linear function between the absolute lowest score and the highest score, as common in this method (Bennagen et al., 2005; Vogdt 1983). The final score $S_{j}$ of each cooking technology analysed $A_{j}$ was calculated by multiplying each indicator $a_{i, j}$ for the weight $w_{1, \ldots, 4}$ of the correspondent criterion $C_{1, \ldots 4}$ as expressed by the equation below. 


$$
S_{j}=\sum_{i=1}^{4} w_{i} * a_{i, j}
$$

Table 1 illustrates the evaluation matrix employed. The weight systems considered are presented in the following paragraphs.

\section{INSERT TABLE 1 HERE}

\subsubsection{Weight systems and sensitivity analysis}

The weight system was set in order to rank the various criteria considered according to their relative importance. As the evaluation of the appropriateness was the main objective of this analysis, the weights were determined using the weighted sum method, as this approach is suitable for single dimensional issues and has been applied in other similar studies (Wimmler et al., 2015; Marler and Arora, 2010). Specifically, a ranking methods approach was employed (Yoon and Hwang, 1995), where different objective functions were ordered by importance, based on feedback from the experts considering the advantages of an improved cooking stove, grouped according to the four clusters identified as evaluation criteria. The least important objective received a weight of 1 , and integer weights with consistent increments are assigned to objectives that were more important. . The total score of each cluster, expressed as a share of the total number of points assigned, was taken as an indicator of the users' priorities, and, thus, as a value of the relative weight in the analysis. The outputs were compared to those obtained varying the weights according to three different perspectives, namely a:

- 'Flat' system (the same weight assigned to all the criteria)

- System structured according to the priorities set by a pool of experts in the sector. In order to structure this second weight system, a number of structured interviews were conducted with researchers and people involved in the household energy sector. The interviewees were asked to assign a score out of 100 points to the positive features of an improved cooking system 
- System structured in order to take into account the point of view of the international scientific community. A review of the literature matching the word 'cook stove' in their title or key words, published since 2009 was undertaken, using the ISI Web of Knowledge database. If the topic or the aspects discussed in the paper matched, a point was assigned to clusters considered in this analysis. The final weight system was given to each cluster as a share of the total sum of points assigned.

The use of alternative stoves (mlc rice husk and solar cooker) is assumed not to fully cover the total energy needs. Thus in the calculations it covered only $33 \%$ of the total. The other $66 \%$ was covered by traditional device (three stone fire) or by the Centrafricain ICS. The Centrafricain ICS was taken as reference improved technology, given its successful previous use (Vitali and Vaccari, 2013).

\section{Results}

\subsubsection{Criteria indicators}

\subsubsection{1. $\quad C_{1}$ financial impact: cooking energy expenditure}

The solar cooker and the biodigester had very high capital costs (Table 2). This was due to the costs of the materials needed for the construction that were difficult to find in the local market or were imported. In particular despite the simplicity of the biodigester system, the cost of the plant was about 300,000 CFA francs (approximately \$US320). Materials for construction were imported from Nigeria and this inevitably affected the final price. Some 80,000 CFA francs (approximately \$US87) was the price subsidized by some local NGOs in the country for the promotion of the parabolic solar cooker, otherwise capital costs would have been higher. The capital cost of $m l c$ rice husk stove was estimated to be 7,000 CFA francs (approximately \$US7.5), based on the prices observed on site for the materials required for the construction. A straight line depreciation method was used to calculate the depreciation expenses for the reference year, taking into account the useful life of each technology. 
The three-stone fire and the LPG stove with similar values, fell into the category of the highest cooking energy expenditure per year. The use of improved cooking stove, in particular the Centrafricain model, allows a significant reduction of cooking energy expenditure. It is less convenient than the adoption of ICS, with a lower overall efficiency (similar to the Ceramic model). The adoption of alternative systems results is more financially beneficial only if used with the ICS. The best indicator was observed for the biodigester, even if some concerns remain about the effective possibility of implementation on a large scale.

\subsubsection{2. $\quad C_{2}$ health impact: exposure to $\mathrm{CO}$ indoor concentration}

The effectiveness of the withdrawal of smoke through the chimney of the mlc rice husk burner was confirmed by apposite measurement taken during the laboratory tests, with the average CO concentration associated with the use of $m l c$ rice husk stove being equal to $4 \mathrm{ppm}$. An average daily cooking time of 4 hours was observed in households using the Centrafricain ICS. As shown in Table 3, gas stoves were the best performing options according to this criterion, with an estimated exposure to CO significantly lower than other wood based energy technologies.

INSERT TABLE 3 HERE

\subsubsection{3. $\mathrm{C}_{3}$ environmental impact: $\mathrm{CO}_{2}$ eq emissions}

The three-stone fire had the highest environmental impact (Table 4). Alternative systems (even if based on totally renewable resources), were not the best performing under this point of view, being complementary in the household energy mix to wood based technologies. Gas based systems had the best indicators, resulting in a magnitude lower amount of emissions than other energy technologies.

INSERT TABLE 4 HERE

3.1.1.4. C $C_{4}$ social impact: concordance with users' preferences 
Social impact was evaluated ranking the different stove models according to the concordance with the preferences pointed out by users. Alternative systems, including biodigesters, produced the least favourable options for the users (Table 5). In particular it was observed that women did not like to use the solar cookers as this technology has to be used in an open space, depriving them of their own private space in the kitchen. The $m l c$ rice husk burner is difficult to use due to the specific operational mode (batch system). However, LPG, though not being widely used, better matched some users' preferences. Local householders identified several disadvantages and negative constraints in using the traditional three stone fire. The disadvantages and constraints of the technologies are captured by the score structured for the analyses.

\section{INSERT TABLE 5 HERE}

\subsubsection{Weight systems adopted}

The key aim of this work was to assess the appropriateness of an energy technology to the local context studied. Thus, the weight system was structured in such a manner as to best address the priorities perceived by householders. Indeed householders are the stakeholders in charge of the choice and of the sustained adoption of an energy technology. Apart from the technical and financial factors, the behaviours and the perceptions of the users play a key role in the successful uptake of a cooking system. The advantages of an improved cooking stove pointed out by users were grouped in the four main clusters identified as evaluation criteria. This choice reflects the strict point of view of the users, thus, a sensitivity analysis was employed. Figure 2 illustrates the different weight systems, which describe the different perceptions of the local users in comparison with the ones of the group of the 10 experts involved in the survey. Community interest was focused on environmental and health related aspects of the use of improved stoves, while users' priorities were towards aspects related to the adaptability to local traditional practices and financial savings.

INSERT FIGURE 2 HERE 


\subsubsection{Assessment of appropriateness}

The evaluation matrix was crossed with different weight systems adopted in order to assess the overall impact in the local context of the different technologies analysed (Figure 3).

\section{INSERT FIGURE 3 HERE}

The alternative technologies resulting in the lowest values, and thus mapping most closely to the criteria set, were the biodigester, the Centrafricain ICS and the combination of this last option with alternative systems. While uncertainty may affect these results for the biodigester option (due to assumptions made in the calculations), the outputs of the analysis underline the appropriateness of the Centrafricain ICS for the local context, in particular according to users' priorities. In addition, the introduction of $m l c$ rice husk stove is likely to best meet the users' preferences. The use of the three-stone fire stove lead to the worst options according to all the weight systems, and it also negatively influenced the adoption of the alternative systems. LPG is a good option according to the experts' weight system, mainly due to the reduced impact on the environment and health. On the contrary, in the users' preference, LPG is not an appropriate technology, as was evidentfrom the limited use of this cooking system in the local context. Further sensitivity analyses were performed excluding each time a single criterion. Thus, the total score of each cooking technology considered was re-calculated subtracting each time one out of the four criteria considered. The outputs of the analysis are reported in Figure 4.

INSERT FIGURE 4 HERE

Excluding the financial criterion, it is evident that the Centrafricain ICS best matched the users' priorities. Alternatively, the biodigester option loses rank among the most appropriate technologies, with a high 
negative impact. The LPG stove, mlc stove and Ceramic ICS produced scores closest to that of the threestone fire.

The use of the Centrafricain ICS alone or in combination with the $m l c$ stove is the most appropriate option excluding the environmental aspect (Figure 5). LPG or alternative energy sources (solar and waste biomass) result in a similar final score to the three-stone fire, while other solutions, such as the biodigester or the Ceramic ICS are slightly more convenient. Similar considerations can be done also excluding the health aspects. The exclusion of the social criteria (and therefore the preferences expressed by the users) highlights that promising technologies, which are often promoted by cooperation intervention (such as biodigesters, solar devices and alternative fuel systems), produce the best scores.

\section{INSERT FIGURE 5 HERE}

\section{Discussion}

The main finding of the study was that the Centrafricain ICS stove alone or in combination with the mlc stove, was the most appropriate cooking technology for use in the case study region (Figure 5). The Centrafricain best matched the users' preference. Alternatively, the biodigester had a high negative impact, and the LPG stove, mlc stove and Ceramic ICS produced scores close to that of the three-stone fire stove. The mlc rice husk burner was difficult to use due to the specific operational mode (batch system). In addition, there was also the intrinsic limited use, in particular if not associated to another improved system. Thus the improved wood cookstove, possibly in combination with an alternative stove would be more appropriate than the traditional cooking system of the three-stone fire stove.

This finding of the appropriateness of the Centrafricain ICS, over the other two ICS stove models, namely a rice husk stove and a parabolic solar cooker, therefore not only confirms the importance of fuel wood as a primary energy source (Harmim et al., 2014; Sosa et al., 2014), but also the potential benefits of using this particular ICS (Parmigiani, 2012; Vitali and Vaccari, 2013).The Centrafricain is a simple, but effective stove. 
The use of the stove, in conjunction with fire wood as a fuel source, is therefore one that should form a key and viable policy recommendation for such rural settings as was the case with the case study region. LPG is more affordable and appropriate in urban areas, where wood fuel was being purchased at the time of the study. However, for many rural consumers who do not participate in the monetized economy, the use of the Centrafricain stove would not only serve as an effective source of energy, but would also map well to traditional systems for cooking (Sosa et al., 2014). In addition, it was observed that women did not like to use the solar cookers as this technology has to be used in an open space, depriving them of their own private space in the kitchen. The use of the Centrafricain stove with its lower rates of emissions, would overcome these concerns, and thus should have a higher uptake amongst women, who are the key stakeholders for cooking. However, risks posed by emission levels (for instance indoor air pollutant concentrations) and exposition time (i.e. the time spent in the kitchen or close to the fire), relate to users' behaviours and the role of individual household members in cooking. In this context, it was the females who were more likely to be the ones undertaking the cooking duties and therefore more at risk. Thus an undesired effect registered in some cases was that the increased livelihood of indoor spaces (due to reduction of smoke thanks to the adoption of improved systems) allowed females to spend more time inside the house, but also resulted in increased exposition time, and therefore potentially higher exposure to IAP. However, it is difficult to effectively model these issues and understanding them would require further study, particularly of the social factors surrounding cooking.

Systems such as the LPG stoves or the Ceramic ICS were promoted on site with variable outcomes, due to specific local (e.g. easy access to wood for free in the rural areas) or user-dependent factors (such as individual preferences, financial capacities). This variability in outcomes can be realized by the ranges of appropriateness score of these stoves overlapping with that for the three-stone fire. The adoption of anaerobic digestion appears to be a promising option, even if its appropriateness to the local context may result in different issues that would have to be further assessed. LPG is the technological option with the more evident change in rank according to the two different weight systems. The high local costs and the reduced perception of its advantages (mainly related to low air quality impacts, both in terms of environmental and users' health aspects) by the local population made this option among the least preferred. 
On the other hand, LPG ranked as one of the most valuable options taking into account the experts' weighting system. Therefore, it should be given consideration when developing household energy strategies at national or regional level. However, since users' priority is financial impact (as shown in Figure 2), LPG stoves could not be heavily used in rural areas because the costs, which are already high in urban areas, would be even higher, because of the transportation and the lower demand.

Unlike previous projects, this study also evaluated GHG emissions. The inclusion of GHG emissions, rather than solely $\mathrm{CO}_{2}$ enabled a broader scope of potential public health impacts to be taken into account. Similar to previous studies, the use of improved stoves were shown to result in reduced GHG emissions (Lee et al., 2013; Lewis et al., 2015).

Given the wide range of criteria that could potentially be used, the results suggest that the four clusters of criteria (i.e. health, environmental financial and environmental), employed were effective in evaluating the selected technologies. Thus similarly to other writers (e.g. Karanfil 2009; Li et al., 2011; Vitali et al., 2013; Parmigiani et al, 2014), a holistic approach that goes beyond solely technical and financial factors is important. The combination of four clusters of criteria, coupled with the views of the experts enabled reliability and validity of the findings and analyses. Indeed, this is an approach that the authors recommend could be employed in other similar projects to ensure validity and reliability in these studies. The range of alternatives and criteria adopted is not exhaustive given the complexity of the factors influencing energy access at household level. However, the approach provides a wide and comprehensive view of the issues. The weight systems adopted were chosen in order to consider the features of each technology according primarily to their relevance to the local needs and the users' perceptions, which inevitably addresses their choices.

A sensitivity analysis taking into account a weight system based on priorities listed by a group of energy experts marked some relevant differences between the points of view of people working in the sector, and those who were supposed to adopt and use the technology. Community interest was focused on environmental and health related aspects of the use of improved stoves, while users' priorities were more 
geared towards aspects related to the adaptability to local traditional practices and financial savings. Thus in the development of policies and strategies, consideration for the varying priorities of key stakeholders involved in the decision making processes as it relates to the choice and use of different cooking technology is therefore crucial.

\section{Conclusions and policy implications}

Despite the high usage of petroleum based fuels globally, the vast majority of people in developing countries will go on relying on traditional solid fuels in future (Li et al., 2011; Bruce et al., 2013; WHO, 2016). Therefore, the use of more effective and improved biomass cooking system is likely to be a more appropriate solution for the provision of household energy in these contexts. There are four key interrelated policy related factors that this study has demonstrated. First, decision-making as regards the choice of the stove to employ should employ a holistic approach. This should take account of the protection of the environmental and public health of the community, coupled with adaptability to local cooking practices, the reliability of the technologies and their economic viability. These were amongst the key issues identified by the households. Indeed, transferring appropriate environmentally sound technologies and ensuring their effective implementation particularly in rural contexts can help to mitigate the rise in the GHG emissions from developing countries. However, to be successful, the technologies must match the lifestyles and requirements of the local community, and be cost effective. For example, the preference of women (who are often the main cooks in these contexts), for privacy during cooking, their interaction with their families, and the potential risks posed by the type of stoves used, as well as their affordability should be built into the policy mix. Thus there should be close engagement with communities, particularly women during the development and implementation of policies. Second, in rural context such as this case study, the Centraficain stove should be utilised as the main type of stove. However, it should be used in conjunction with the use of fire wood as a fuel source. At the same time, while LPG was the less preferred option due to its high costs and the lower perceptions about its positive impact on health, it should nevertheless be included in any policy mix, as cost differentials and appropriateness depend on rural versus urban considerations. Third, there is a need for a stronger use of scientific evidence to inform the development of energy policy in developing 
countries. It is only in this way that policies and strategies can best be made more effective. Linked to this, should be awareness raising amongst not only households, but also community organisations and donor agencies who have significant influence on the decision-making and choice of stoves. This awareness raising might for example, be achieved through the use of training workshops held within the community and involving all key stakeholders.

Finally, from a methodological perspective, the use a holistic approach to the evaluation of the technologies, coupled with the contextualization from experts and users worked well. Therefore, as also argued in previous studies, this is an approach that should be adopted in future projects.

\section{Authors' contribution}

Mentore Vaccari set up and supervised the research. Francesco Vitali carried out data collection and, with Mentore Vaccari, data analysis and elaboration. Terry Tudor contributed to results, discussion and policy implications.

\section{Acknowledgements}

This research was developed within the $\mathrm{PhD}$ course in "Appropriate Methods and Technologies for International Development Co-operation" of the University of Brescia, supported by the Alberto Archetti Fund, and the PhD course in "Technologies and energy systems for the mechanical industry".

The study was partially conducted through the activities of an international development cooperation project led by the Italian NGO, ACRA and funded by the European Union (Projet de gestion participative des ressources forestières dans la vallée du Logone - ENV/2006/114-747). The authors wish to thank the Italian and the local staff of ACRA for their support during the field activities in Chad and Cameroon. 


\section{References}

Arnold, J.E.M., Kohlin, G., Persson, R., 2006. Woodfuels, livelihoods and policy interventions: changing perspectives. World Dev. 34 (3), 596-611.

Bansal, M., Saini, R.P., Khatod, D.K., 2013. Development of cooking sector in rural areas in India-A review. Ren and Sus Ene Rev.17, 44-53

Bennagen, M.E., Indab, A., Amponin, A., Cruz, R., Folledo, R., van Beukering, P.J.H., Brander, L., Hess. S., van Soesbergen, A., van der Leeuw, K., de Jong, J. 2005. Designing payments for watershed protection services of Philippine upland dweller. Available online at http://www.premonline.nl.

Bruce, N.G., Rehfuess, E.A., Smith, K.R. 2013. Household Energy Solutions in Developing Countries. Nriagu JO (ed.) Encyc Env Health. 3, 62-75.

Correa, F., González, M., Servín, H., Márquez, F., Rutiaga, J.G., Lemus, A.A., Reguera, E., Alonso, V. 2014. Development of a Selective Low Cost Absorbing Surface based on Soot for Solar Thermal Applications. Ene Procedia. 57, 1565-1572

Debnath, R., Bardhan, R., Banerjee, R. 2016. Investigating the age of air in rural Indian kitchens for sustainable built-environment design. J Build Eng. 7, 320- 333.

García-Frapolli, E., Schilmann, A., Berrueta, V.M., Riojas-Rodríguez, H., Edwards, R.D., Johnson, M., Guevara-Sanginés, A., Armendariz, C., Masera, O., 2010. Beyond fuelwood savings: Valuing the economic benefits of introducing improved biomass cookstoves in the Purépecha region of Mexico. Ecol Eco. 69 (12), 2598-2605

Ghilardi, A., Guerrero, G., Masera, O., 2009. A GIS-based methodology for highlighting fuelwood supply/demand imbalances at the local level: A case study for Central Mexico. Biomass and Bioenergy. $33,(6-7), 957-972$

Giuntoli, J., Caserini, S., Marelli, L., Baxter, D., Agostini, A., 2015. Domestic heating from forest logging residues: environmental risks and benefits. Journal of Cleaner Production, Volume 99, Pages 206-216

Harijan K, Uqaili MA. 2013. Potential of biomass conservation through dissemination of efficient cook stoves in Pakistan. APCBEE Procedia. 5, 358-362. 
Harmim, A,, Merzouk, M., Boukar, M., Amar, M., 2014. Solar cooking development in Algerian Sahara: Towards a socially suitable solar cooker. Ren Sus Energy Rev. 37, 207-214

Hiemstra-van der Horst, G., Hovorka, A.J., 2008. Reassessing the “energy ladder”: Household energy use in Maun, Botswana. Ene Pol. 36 (2008), $3333-3344$

IEA (International Energy Agency), 2015. World energy outlook. http://www.worldenergyoutlook.org/weo2015/ (accessed 10.02.2017)

Ilskog, E., Kjellström, B. 2008. And then they lived sustainably ever after? - assessment of rural electrication cases by means of indicators. Ene Pol. 36, $2674-84$.

Johnson, M., Edwards, R., Ghilardi, A., Berrueta, V., Gillen, D., Alatorre Frenk, C., Masera, O. 2009. Quantification of Carbon Savings from Improved Biomass Cookstove Projects. Env Sci Tech. 2009, 43, $2456-2462$.

Karanfil, F. 2009. How many times again will we examine the energy-income nexus using a limited range of traditional econometric tools? Ene Pol. 37 (2009), 1191 -1194

Kahraman, C., Kaya, I. 2010. A fuzzy multicriteria methodology for selection among energy alternatives. Exp Sys Apps. 37 (2010), 6270-6281.

Kowsari, R., Zerriffi, H. 2011. Three dimensional energy profile: a conceptual framework for assessing household energy use. Ene Pol. 39 (2011), 7505 -7517.

Kucerova, I., Banout, J., Lojka, B., Polesny, Z. 2016. Performance evaluation of wood-burning cookstoves in rural areas near Pucallpa, Peru. Environmental Engineering and Management Journal 15 (11), 24212428.

Kumar, A., Sah, B., Singh, AR., Deng, Y., He, X., Kumar, P. 2017. A review of multi criteria decision making (MCDM) towards sustainable renewable energy development. Rene Sus Ene Rev. 596 - 609.

Kwofie, E.M., Ngadi, M., Sotocinal, S. 2017. Energy efficiency and emission assessment of a continuous rice husk stove for rice parboiling. Energy 122, 340-349.

Lee, CM., Chandler, Lazarus, M., Johnson, FX. 2013. Assessing the Climate Impacts of Cookstove Projects: issues in emissions accounting. Stockholm Environment Institute. Available at: https://www.sei-international.org/mediamanager/documents/Publications/Climate/sei-wp-2013-01-

$\underline{\text { cookstoves-carbon-markets.pdf }}$ 
Leavey, A., Londeree, J., Priyadarshini, P., (...), Yadama, G., Biswas, P. 2015. Real-Time Particulate and CO Concentrations from Cookstoves in Rural Households in Udaipur, India. Environmental Science and Technology 49 (12), 7423-7431.

Lewis, JJ., Bhojvaid, V, Brooks, N., Das, I., Jeuland, MA., Patange, O., Pattanayak SK. 2015. Piloting improved cookstoves. J Health Com: Int Perspectives. 20 (1), 28 - 42.

Li, Z., Sjödin, A., Romanoff, L.C., Horton, K., Fitzgerald, C.L., Eppler, A., Aguilar-Villalobos, M., Naeher, L.P. 2011. Evaluation of exposure reduction to indoor air pollution in stove intervention projects in Peru by urinary biomonitoring of polycyclic aromatic hydrocarbon metabolites. Env Int. 37 (7), 1157-1163

Marler, RT., Arora, JS. 2010. The weighted sum method for multi-objective optimization: new insights. Struct Multidiscip Optim. 41, $853-62$.

Mensah, JT., Adu, G. 2015. An empirical analysis of household energy choice in Ghana. Ren Sus Energy Rev. 51, $1402-14011$.

Oanh, N.T.K., Albina, D.O., Ping, L., Wang, X. 2005. Emission of particulate matter and polycyclic aromatic hydrocarbons from select cookstove-fuel systems in Asia. Biomass and Bioenergy. 28 (6), $579-590$

Parmigiani, S., 2012. Appropriate technologies for an emancipating cooperation: the development of an effective improved cook-stove. Thesis in the PhD course "Tecnologie e sistemi energetici per l'industria meccanica" Faculty of Engineering, University of Brescia.

Parmigiani, S.P., Vitali, F., Lezzi, A.M., Vaccari, M. 2014. Design and performance assessment of a rice husk fueled stove for household cooking in a typical sub-Saharan setting. Ene Sus Dev. 23, 15-24

Patel, S., Khandelwal, A., Leavey, A., Biswas, P. 2016. A model for cost-benefit analysis of cooking fuel alternatives from a rural Indian household perspective. Ren Sus Energy Rev. 56, 291-302

Pohekar, S.D., Ramachandran, M. 2006. Utility assessment of parabolic solar cooker as a domestic cooking device in India. Ren Ene. 31 (11), 1827-1838

Practical Action 2011. Sphere Handbook. Available at: http://practicalaction.org/page/2207 
Sosa, L.B.L., Avilés, M.G., Pérez, D.G., Gutiérrez, Y.S., 2014. Rural solar cookers, an alternative to reduce the timber resource extraction through the use of renewable energy sources: technology transfer and monitoring project. Ene Procedia. 57, 1593-1602.

Venkatamaran, C., Sagar, A.D., Habib, G., Smith, K. 2010. The National Initiative for advanced biomass cookstoves: the benefits of clean combustion. Ene Sus Dev. 14(2), 63-72

Vaccari, M., Vitali, F., Mazzu, A., 2012. Improved cookstove as an appropriate technology for the Logone Valley (Chad and Cameroon): analysis of fuel and cost savings. Ren Ene. 42, 45 - 54.

Vitali, F., Parmigiani, S., Vaccari, M., Collivignarelli, C. 2013. Agricultural waste as household fuel: Techno-economic assessment of a new rice-husk cookstove for developing countries. Waste Manag. 33 (12), 2762-2770

Vitali F., Vaccari M. 2013. Appropriate technology for household energy access: the case of the Centrafricain stove in the Logone Valley (Chad, Cameroon). In: (eds.) Boulay J, Hostettler S., Hazboun E. Technologies for Sustainable Development: a way to reduce poverty. 129 - 140. Springer International Publishing.

WEO (World Energy Outlook) 2016. Energy and Air Pollution. World Energy Outlook Special Report. http://www.iea.org/publications/freepublications/publication/weo-2016-special-report-energy-and-airpollution.html (accessed 10.02.2017)

WHO (World Health Organization) 2010. WHO guidelines for indoor air quality: selected pollutants. The WHO European Centre for Environment and Health, Bonn Office, Germany.

WHO (World Health Organization) 2016. Household air pollution and health. Available at: http://www.who.int/mediacentre/factsheets/fs292/en/ accessed on 22/2/2017

Wimmler, C., Hejazi, G., de Oliveira Fernandes, E., Moreira, C., Connors, S. 2015. Criteria decision support methods for renewable energy systems on islands. J Clean Ene Tech. 3, 185 - 95.

Yoon, KP., Hwang, C-L. 1995. Multiple attribute decision making, an introduction. Sage. London 